\title{
COMPULSIVE BUYING AND RELATED MOTIVES: ENHANCEMENT AND COPING
}

\author{
Kuntay Arcan \\ Psychology Department, Maltepe University, Istanbul (Turkey)
}

\begin{abstract}
Background: Research indicates that compulsive buying that refers to chronic, excessive shopping and expenditure isn't rare, especially among the young people. However, related studies are limited. More research is required to advance our understanding about the phenomenon and to improve prevention and treatment strategies.

Objectives: This study especially aimed to investigate the role of shopping motives for compulsive buying. For this purpose, coping and enhancement motives that were originally developed to assess drinking reasons were adapted for shopping. Examining the relationships of compulsive buying with demographics, spending frequency of different products, positive and negative affect were also other objectives of the study.

Methods: The sample was composed of 362 voluntary university students selected through convenience sampling in Turkey. Majority of the participants were females (77.9\%). The mean age was 21.91 $(\mathrm{SD}=3.11)$. Participants rated the frequency of shopping motives for each of the 5 enhancement items (e.g. to get high, because it's fun) and the 5 coping items (e.g. to forget worries, to relax) on 4 point Likert-scale (1: almost never, 4: almost always). Compulsive Buying Scale, Positive and Negative Affect Schedule were also utilized as standard measurement instruments. The participants rated their spending frequency on different products such as cosmetics, clothes, technological products, or furniture on a 1 to 4 scale (1: almost never, 4: almost always).

Findings: According to the results of the hierarchical multiple regression analysis being female, having younger age and lower GPA ( $1^{\text {st }}$ step) in addition to higher personal income $\left(2^{\text {nd }}\right.$ step), spending frequently for cosmetics, shoes and clothes ( $3^{\text {rd }}$ step), having higher negative affect $\left(4^{\text {th }}\right.$ step) were found to be associated with compulsive buying scores. Moreover, both enhancement and coping motives that were entered into the regression equation in the last step $\left(5^{\text {th }}\right.$ step), also predicted the participants' compulsive buying scores. The total explained variance was $58.2 \%$.

Conclusions: The findings of this study are important to indicate the possible risk factors for compulsive buying including age, gender, income, spending habits, and negative affect. Moreover, the results reveal that buying something in order to enhance positive affect and to avoid negative feelings can be prominent determinants of compulsive buying. Research from non-Western countries such as the present study are essentially important to highlight the associates of compulsive buying across cultures since majority of the relevant literature derive from studies conducted with Western participants.
\end{abstract}

Keywords: Compulsive buying, motives, enhancement, coping, Turkish university students.

\section{Introduction}

Impulsive purchases are common and most of them are not problematic, but repeated experiences of uncontrolled buying may be dysfunctional and problematic (Billieux et al., 2008). Overpowering impulse to buy that is associated with negative consequences is typical for compulsive buyers (O'Guinn \& Faber, 1989). This kind of preoccupation with buying may be distressing and time consuming and it may lead to family, social, vocational or financial difficulties (McElroy et al., 1994). Approximately one in 20 individuals are stated to suffer from compulsive buying negative consequences and thus, it is proposed that buying related problems should not be overlooked (Maraz, Griffiths, \& Demetrovics, 2015). Research of compulsive buying related risk factors especially among young people seems important taking prevalence rates and difficulties at psychological, academic, financial, familiar levels into consideration (Villardefrancos \& Otero-Lopez, 2016).

Emotional distress (depression, anxiety, obsessive compulsiveness) and personal characteristics (low conscientiousness and self-esteem, external locus of control, sensation seeking) together with 
tendency to avoid daily life stress are personal variables that are associated with addictive buying (Rodriguez-Villarino et al., 2006). Evidence of associations between avoiding negative feelings and addictive behaviors are also present in the relevant addiction literature including alcohol, substance use, or gambling research (e.g. Mcnally et al., 2003; Simons, Correia, \& Carey, 2000, Simons et al., 2016; Wood \& Griffiths, 2007). Motivational model of alcohol use suggests that people also drink to enhance positive emotions as well as to cope with negative emotions (Cooper et al., 1995). Related research supports the relation of enhancement motive and drinking alcohol (e.g. Kuntsche, von Fischer, \& Gmel, 2008; Stevenson et al., 2019). Similar findings that indicate association between enhancing positive emotions and gambling are also present in the relevant literature (Jaurequi et al., 2020).

Taking into consideration the role of motivational factors in the addiction literature as briefly outlined above, major purpose of the present study was to investigate the predictive role of shopping motives for compulsive buying. Thus, enhancement and coping motives that were developed to assess drinking reasons (Cooper et al., 1992) were adapted in order to assess shopping motives for the present study. Income, spending frequency on different products, positive and negative affect were the other variables of the study in addition to the demographics of the participants. The sample was composed of university students taking into consideration the relevant research results that indicate the presence of possible problems among them in various studies conducted in different countries (e.g. Duroy, Gorse, \& Lejoyeux, 2014; Villardefrancos \& Otero-Lopez, 2016). The major expectation was to contribute to the development of preventive and treatment programs about compulsive buying by determining the possible risk factors among the Turkish university students.

\section{Methods and materials}

\subsection{Sample and procedure}

The sample of this cross-sectional survey was composed of 362 voluntary university students selected through convenience sampling in Turkey. The study was conducted in 2018. Participation was voluntary and withdrawal at any time of the study was possible. Participants signed a written informed consent including this information. The instrument set was completed on the average in 20 minutes.

The majority of the participants were females (77.9\%). They were almost four times of the male participants $(22.1 \%)$. The mean age of the participants was $21.91(\mathrm{SD}=3.11)$. Most of the participants were undergraduate students in Faculty of Humanities and Social Sciences $(51.4 \%)$ and Faculty of Education (43.1\%). The majority of them were studying Psychology (49.2\%) and Guidance and Psychological Counseling (38.4\%).

\subsection{Materials}

Demographics \& Spending Form:

This form consisted of information about demographical variables and spending frequency of the participants. Demographical variables were age, sex, GPA, department, household and personal income. Additionally, the participants rated their spending frequency on different products on a 1 to 4 scale (1: almost never, 4: almost always) in this form. These products were cosmetics, shoes and clothes, accessory and jewelry, technological products, stationery, souvenir, and furniture.

\section{Buying Motives:}

In order to assess the buying motives of the participants in the present study, coping and enhancement motives that were developed for drinking literature were adapted for shopping. Five items for coping and five items for enhancement that were utilized for the present study were validated for alcohol use reasons in addition to social (Cooper et al., 1992) and conformity (Cooper, 1994) motives. It was assumed that coping and enhancement motives would be compatible as buying reasons rather than social and conformity motives. Relative frequency of drinking for different reasons (e.g. enhancement: because it's exciting, because it's fun; coping: to forget about your problems, because it helps when you feel depressed or nervous) were rephrased and asked for relative frequency of shopping reasons considering the purpose of the present study. The participants rated those shopping reasons on a 1 to 4 scale (1: almost never / never, 2: sometimes, 3: usually, 4: almost always / always). The internal consistency values were computed as .87 and .90 for enhancement and coping shopping motives respectively for the present study. These values were compatible with the Cronbach's alpha scores reported for the original versions (Cooper, 1994; Cooper et al., 1992) and the Turkish version (Evren et al., 2010) of scale that focused on drinking motives.

Compulsive Buying Scale:

Compulsive Buying Scale was developed by Valence, D'astous and Fortier (1998) and adapted into Turkish by Yüncü and Kesebir (2014). Items of the scale are about tendency to spend money (e.g. "I sometimes feel that something inside pushed me to go shopping."), expectancy about shopping 
(e.g. "For me shopping is a way of facing the stress of my daily life and relaxing."), or results of shopping (e.g. "At times, I have felt somewhat guilty after buying a product, because it seemed unreasonable."). Internal consistency value for the Turkish version of the scale was reported as .80. Twelve items of the scale were rated on a 5 point Likert-scale in the present study (1: never, 5: always). Higher scores on the scale indicate that the participants are more compulsive buyers.

The Positive Affect Negative Affect Schedule (PANAS):

PANAS was developed by Watson, Clark and Tellegen (1988) and adapted into Turkish by Gencöz (2000). The scale has 20 items. Positive affect (e.g. interested, proud, inspired) and negative affect (e.g. upset, guilty, scared) items are rated on a 5 point Likert scale (1: very slightly or not at all, 5: extremely). Internal consistency values were reported as .83 and .86 for positive affect and negative affect respectively for the Turkish version of the scale. Higher scores on the subscales indicate that the participants feel more positively and negatively.

\section{Results}

The participants rated their spending frequency on different products excluding their basic needs on a 1 to 4 scale (1: almost never, 4: almost always) as shown in Table 1. The most common "(almost) always" answers were observed for shoes \& clothes, cosmetics, and stationery products respectively. These rankings were same for the "usually" ratings. On the other hand, the most common "(almost) never" answers were observed for furniture, accessory \& jewelry, and technological products in respect.

Table 1. Spending frequency of the participants.

\begin{tabular}{lcccc}
\hline & (almost) never & sometimes & usually & (almost) always \\
\hline cosmetics & $54(14.9 \%)$ & $159(43.9 \%)$ & $109(30.1)$ & $37(10.2 \%)$ \\
shoes \& clothes & 0 & $98(27.1 \%)$ & $198(54.7 \%)$ & $66(18.2 \%)$ \\
accessory \& jewellery & $73(20.2 \%)$ & $205(56.6 \%)$ & $71(19.6 \%)$ & $10(2.8 \%)$ \\
technological products & $67(18.5 \%)$ & $228(63.0 \%)$ & $45(12.4 \%)$ & $19(5.2 \%)$ \\
stationery & $52(14.4 \%)$ & $192(53.0 \%)$ & $87(24.0 \%)$ & $28(7.7 \%)$ \\
souvenir & $34(9.4 \%)$ & $256(70.7 \%)$ & $58(16.0 \%)$ & $14(3.9 \%)$ \\
furniture & $225(62.2 \%)$ & $120(33.1 \%)$ & $13(3.6 \%)$ & $1(0.3 \%)$ \\
\hline
\end{tabular}

Mean scores of compulsive buying, negative affect, positive affect, enhancement and coping buying motives were computed for the participants and correlations of these scores were analysed. Compulsive buying scores of the participants were positively and significantly correlated with their negative affect $(r=.20, p<.001)$, enhancement $(r=.73, p<.001)$ and coping $(r=.66, p<.001)$ motives scores. These results are shown in Table 2 including the internal consistency values of the scales.

Table 2. Descriptive statistics and correlations.

\begin{tabular}{|c|c|c|c|c|c|c|c|c|}
\hline & Mean & $S D$ & Cronbach's $\alpha$ & 1 & 2 & 3 & 4 & 5 \\
\hline 1. compulsive buying & 2.25 & 0.74 & 0.88 & 1.00 & & & & \\
\hline 2. negative affect & 2.02 & 0.58 & 0.80 & $.20 * *$ & 1.00 & & & \\
\hline 3. positive affect & 3.33 & 0.59 & 0.77 & .07 & $-.12 *$ & 1.00 & & \\
\hline 4. enhancement & 2.03 & 0.64 & 0.87 & $.73 * *$ & .04 & .08 & 1.00 & \\
\hline 5. coping & 1.91 & 0.67 & 0.90 & $.66 * *$ & .03 & .03 & $.79 * *$ & 1.00 \\
\hline
\end{tabular}

A hierarchical multiple regression analysis was performed to determine the predictors of the participants' compulsive buying scores. It was especially aimed to test the additional contributions of enhancement and coping motives on compulsive buying scores after controlling for the effects of the other study variables. Gender, age, GPA were entered into the equation in the first step. Household and personal income that were entered into the equation in the second step preceded the spending frequency of the participants on different products. Finally, negative and positive affect scores were entered as the fourth and buying motives (enhancement \& coping) scores were entered as the fifth steps into the regression analysis. As can be seen in Table 3, all steps statistically contributed to the compulsive buying scores of the participants $(F<.001)$. Being female, having younger age, lower GPA and higher personal income were associated with higher compulsive buying scores. Spending more frequently for cosmetics, shoes and clothes that were regressed in the third step of the equation and higher negative affect that was regressed in the fourth step were also associated with higher compulsive buying scores. Enhancement and coping motives that were entered into the equation in the last step incremented the explained variance of compulsive buying scores more than the variables of the prior steps as can be followed from the $R^{2}$ values. The results of the regression analysis are detailed in Table 3. 
Table 3. Variables associated with compulsive buying according to the results of the regression analysis.

\begin{tabular}{|c|c|c|c|c|c|c|}
\hline & $\beta$ & $t$ & $R^{2}$ & $\operatorname{Adj} . R^{2}$ & $F$ & F change \\
\hline Step 1 & & & .086 & .078 & $11.17 * * *$ & $11.17 * * *$ \\
\hline gender & -.23 & $-4.39 * * *$ & & & & \\
\hline age & -.11 & $-2.07 *$ & & & & \\
\hline GPA & -.18 & $-3.49 * *$ & & & & \\
\hline Step 2 & & & .118 & .105 & $9.48 * * *$ & $6.45 * * *$ \\
\hline personal income & .21 & $3.43 * *$ & & & & \\
\hline Step 3 & & & .226 & .199 & $8.49 * * *$ & $6.98 * * *$ \\
\hline cosmetics & .31 & $4.91 * * *$ & & & & \\
\hline shoes \& clothes & .12 & $2.10^{*}$ & & & & \\
\hline Step 4 & & & .266 & .236 & $8.97 * * *$ & $9.39 * * *$ \\
\hline negative affect & .19 & $4.05 * * *$ & & & & \\
\hline Step 5 & & & .600 & .582 & $32.37 * * *$ & $144.318^{* * *}$ \\
\hline enhancement & .48 & $7.98 * * *$ & & & & \\
\hline coping & .26 & $4.63 * * *$ & & & & \\
\hline
\end{tabular}

\section{Conclusion}

The findings of the present study suggested that being young and female were risk factors for compulsive buying among Turkish university students. Similar results are already present in the relevant literature (e.g. Ditmar, 2005). In addition, lower GPA seemed to be another associate of compulsive buying according to the results of the present study supporting the previous research (e.g. Harvanko et al., 2013). Preoccupation with buying may result in academic difficulties for some of the university students. At the same time, compulsive buying behavior may be increasing in order to avoid low academic performance related stress. Higher personal income and spending more frequently for cosmetics, shoes and clothes were the other predictors of compulsive buying. Clothes, shoes, or cosmetics purchases are also reported as usual among compulsive buyers in previous studies (e.g. Christenson et al., 1994; Miltenberger et al., 2003). The participants of the present study were relatively young people and majority of them were single. Thus, most of them were not probably responsible for meeting other family members' economic needs. In other words, they were presumably more 'free' to spend their money for themselves. Considering the participants' economical responsibilities for others in future research may clarify the association between income and compulsive buying. After controlling for the effects of all these variables, negative affect together with enhancement and coping motives predicted the compulsive buying scores of the sample. It seems negative emotions may be motivating compulsive buying and decrease in negative affect and increase in positive affect may be maintaining the problem as Miltenberger and colleagues (2003) suggest. The results of the present study are especially important to reveal the robust predictive role of affect regulation motives on the compulsive buying behavior after controlling for the effects of demographics, income, purchased items, positive and negative affect. The contribution of enhancement and coping motives on explained variance of compulsive buying was more than the contribution of the other study variables although those variables were entered into the regression equation in the preceding steps.

\section{References}

Billieux, J., Rochat, L., Rebetez, M. M. L., \& Van der Linden, M. (2008). Are all facets of impulsivity related to self-reported compulsive buying behavior? Personality and Individual Differences, 44(6), 1432-1442.

Christenson, G. A., Faber, R. J., de Zwaan, M. Raymond, N. C., Speckers, S. M., Ekern, M. D., Mackenzie, T. B., Crosby, R. D., Crow, S. J., \& Eckert, E. D. (1994). Compulsive buying: Descriptive characteristics and psychiatric comorbidity. The Journal of Clinical Psychiatry, 55(1), 5-11.

Cooper, M. L. (1994). Motivations for alcohol use among adolescents. Development and validation of a four-factor model. Psychological Assessment, 16(2), 117-128.

Cooper, M. L., Frone, M. R., Russell, M., \& Mudar, P. (1995). Drinking to regulate positive and negative emotions: A motivational model of alcohol use. Journal of Personality and Social Psychology, 69(5), 990-1005

Cooper, M. L., Russell, M., Skinner, J. B., \& Windle, M. (1992). Development and validation of a three-dimensional measure of drinking motives. Psychological Assessment, 4(2), 123-132. 
Ditmar, H. (2005). Compulsive buying - a growing concern? An examination of gender, age and endorsement of materialistic values as predictors. British Journal of Psychology, 96(4), 467-491.

Duroy, D., Gorse, P., \& Lejoyeux, M. (2014). Characteristics of online compulsive buying in Parisian students. Addictive Behaviors, 39(12), 1827-1830.

Evren, C., Celik, S., Aksoy, R., \& Cetin, T. (2010). Factorial structure, reliability and validity of the Turkish version of the Drinking Motives Questionnaire-Revised in male alcohol dependent patients. Düşünen Adam: The Journal of Psychiatry and Neurological Sciences, 23(3), 174-184.

Gencoz, T. (2000). Positive and negative affect schedule: A study of validity and reliability. Turkish Journal of Psychology, 15(46), 27-28.

Harvanko, A., Lust, K., Odlaug, B. L., Schreiber, L. R. N., Derbyshire, K., Christenson, G., \& Grant, J. E. (2013). Prevalence and characteristics of compulsive buying in college students. Psychiatry Research, 210(3), 1079-1085.

Jaurequi, P., Estevez, A., Macia, L., \& Lopez-Gonzalez, H. (2020). Gambling motives: Association with addictive disorders and negative mood in youth. Addictive Behaviors, 110, DOI: $10.1016 /$ j.addbeh.2020.106482

Kuntsche, E., von Fischer, M., \& Gmel, G. (2008). Personality factors and alcohol use: A mediator analysis of drinking motives. Personality and Individual Differences, 45(8), 796-800.

Maraz, A., Griffiths, M. D., \& Demetrovics, Z. (2015). The prevalence of compulsive buying: A meta-analysis. Addiction, 111(3), 408-419.

McElroy, S. L., Keck, P. E., Pope, H. G., Smith, J. M. R., \& Strakowski, S. M. (1994). Compulsive buying: A report of 20 cases. The Journal of Clinical Psychiatry, 55(6), 242-248.

McNally, A. M., Palfai, T. P., Levine, R. V., \& Moore, B. M. (2003). Attachment dimensions and drinking-related problems among young adults: The mediational role of coping motives. Addictive Behaviors, 28(6), 1115-1127.

Miltenberger, R. G., Redlin, J., Crosby, R., Stickney, M., Mitchell, J., Wonderlich, S., Faber, R., \& Smyth, J. (2003). Direct and retrospective assessment of factors contributing to compulsive buying. Journal of Behavior Therapy and Experimental Psychiatry, 34(1), 1-9.

O’Guinn, T. C., \& Faber, R. J. (1989). Compulsive buying: A phenomenological exploration. Journal of Consumer Research, 16(2), 147-157.

Rodriguez-Villarino, R., Gonzalez-Lorenzo, M., Fernandez-Gozalez, A., Lameiras-Fernandez, M., \& Foltz, M. L. (2006). Individual factors associated with buying addiction: An empirical study. Addiction Research and Theory. 14(5), 511-525.

Simons, J. S., Clarke, C. J., Simons, R. M., \& Spelman, P. J. (2016). Marijuana consequences in a motivational context: Goal congruence reduces likelihood of taking steps toward change. Addictive Behaviors, 52, 83-90.

Simons, J., Correia, C. J., \& Carey, K. B. (2000). A comparison of motives for marijuana and alcohol use among experienced users. Addictive Behaviors, 25(1), 153-160.

Stevenson, B. L., Dvorak, R. D., Kramer, M. P., Peterson, R. S., Dunn, M. E., Leary, A. V., \& Pinto, D. (2019). Within- and between-person associations from mood to alcohol consequences: The mediating role of enhancement and coping drinking motives. Journal of Abnormal Psychology, 128(8), 813-822.

Valence, G., D’astous, A., \& Fortier, L. (1998). Compulsive buying: Concept and measurement. Journal of Consumer Policy, 11, 419-433.

Villardefrancos, E., \& Otero-Lopez, J. M. (2016). Compulsive buying in university students: Its prevalence and relationships with materialism, psychological distress symptoms, and subjective well-being. Comprehensive Psychiatry, 65, 128-135.

Watson, D., Clark, L. A., \& Tellegen, A. (1988). Development and validation of brief measures positive and negative affect: The PANAS scales. Journal of Personality and Social Psychology, 54(6), 1063-1070.

Wood, R. T. A., \& Griffiths, M. D. (2007). A qualitative investigation of problem gambling as an escape-based coping strategy. Psychology and Psychotherapy: Theory, Research and Practice, 80, 107-125.

Yüncü, Z., \& Kesebir, S. (2014). Compulsive Buying Scale: Validity, reliability and its psychometric characteristics in our society. Bă̆ımlılık Dergisi, 15(3), 142-149. 